\title{
A COMPETÊNCIA E A METODOLOGIA INTERPRETATIVO-DECISÓRIA DO TRIBUNAL DE JUSTIÇA DA UNIÃO EUROPÉIA*
}

\author{
JÖRG NEUNER $^{* *}$
}

\begin{abstract}
RESUMO: O Tribunal de Justiça da União Européia desempenha um papel muito importante no processo de integração européia. O objetivo da presente contribuição consiste em analisar suas competências e metodologia interpretativo-decisória, com ênfase no exame da vinculação de seus juízes ao direito legislado e aos precedentes judiciais. PALAVRAS-CHAVE: Tribunal de Justiça da União Européia; Competência; Interpretação.
\end{abstract}

\begin{abstract}
The Court of Justice of the European Union plays a very important role in the european integration process. The following essay aims to examine the competences and the legal reasoning deployed by the Court, emphasizing the analysis of the binding of its judges to law and precedents.

KEYWORDS: Court of Justice of the European Union; Competence; Legal reasoning.

SUMÁRIO: I. Fundamentos; 1. A construção escalonada da Ordem Jurídica; 2. As especificidades do Direito Comunitário; 3. As competências do Tribunal de Justiça da União Européia; II. A Vinculação à Lei; 1. A Dimensão Relativa às Competências; 2. A dimensão Relativa ao Conteúdo; 3. A Dimensão Temporal; III. A Vinculação aos
\end{abstract}

Artigo recebido em 16.12.2009 e aprovado para publicação pelo Conselho Editorial em 30.03.2010.

* O Autor gostaria de registrar seu agradecimento ao Sr. Pedro Scherer de Mello Aleixo, ProfessorAssistente na Universidade de Augsburg, pela tradução do presente texto e pelas valiosas referências para a complementação das notas de rodapé.

O presente artigo consiste em versão, acrescida de notas de rodapé, de duas palestras proferidas pelo Autor em setembro/outubro de 2009 nas Cidades de Porto Alegre (Pontifícia Universidade Católica do Rio Grande do Sul - 30.09) e São Paulo (Congresso Anual de Estudos Constitucionais promovido pelo Instituto Brasileiro de Estudos Constitucionais - 2.10).

Cf. a título meramente ilustrativo da produção bibliográfica existente a respeito do direito comunitário europeu na literatura jurídica portuguesa: Fausto de Quadros, Direito da União Europeia, Coimbra, 2008; Miguel Gorjão-Henriques, Direito Comunitário, 5. ed., Coimbra, 2008; José Luís Caramelo Gomes, Lições de Direito da União Europeia, Coimbra, 2009; cf. ainda, também com caráter meramente exemplificativo, na literatura jurídica brasileira: José Souto Maior Borges, Curso de Direito Comunitário, 2. ed., São Paulo, 2009; Maria Teresa de Cárcomo Lobo, Manual de Direito Comunitário, 3. ed., Curitiba, 2007; José Alfredo de Oliveira Baracho, Teoria Geral do Direito Constitucional Comum Europeu, Revista da Associação dos Magistrados Brasilerios vol. 11 (2001), p. 20 ss. Os trechos de legislação de direito comunitário europeu transcritos no presente artigo foram extraídos do portal oficial da União Européia na internet (http://europa.eu/index_pt.htm).

** Professor Catedrático de Direito Civil, Direito do Trabalho, Direito Comercial e Filosofia do Direito na Universidade de Augsburg - Alemanha. 
Precedentes; 1. A Tomada de Decisão Concreta e Individual; 2. O Princípio da Liberdade Decisória; 3. O Princípio da Proteção da Confiança; IV. Considerações Finais.

SUMMARY: I. Foundations; 1. The Leveled Construction of the Legal Order; 2. The Specificities of EU Law; 3. The European Court of Justice's Competences; II. The Binding to Law; 1. The Competences-related Dimension; 2. The Content-related Dimension; 3. The Time-related Dimension; III. The Binding to Precedents; 1. The Concrete and Individual Decision-making; 2. The Decision-making Freedom Principle; 3. The Protection of Trust Principle; IV. Final Remarks.

O Tribunal de Justiça da União Européia, sediado em Luxemburgo, consiste no órgão judicial supremo da União Européia. ${ }^{1}$ Dele fazem parte, nos termos do art. 19, alínea 2, frase 1, do Tratado da União Européia (TUE), um juiz de cada Estado-Membro; atualmente, portanto, 27 juízes dos 27 Estados-Membros. Além do Tribunal de Justiça da União Européia, há, nos termos do art. 19, alínea 1, do TUE, o Tribunal Geral (de primeira instância), ${ }^{2}$ bem como tribunais especializados (o Tribunal da Função Pública da União Européia). ${ }^{3} \mathrm{O}$ Tribunal de Justiça da União Européia é auxiliado, nos termos do art. 19, alínea 2, frase 2, do TUE, por advogados-gerais. ${ }^{4}$ De acordo com o art. 252, alínea 2, do Tratado sobre o Funcionamento da União Européia (TFUE), ao advogado-geral "cabe apresentar publicamente, com toda a imparcialidade e independência, conclusões fundamentadas sobre as causas que, nos termos do Estatuto do Tribunal de Justiça da União Européia, requeiram a sua intervenção". Ele aduz, após os debates orais, uma proposta de decisão.

\section{FUNDAMENTOS}

A fim de classificar as competências do Tribunal de Justiça da União Européia, precisa-se, primeiramente, delimitar o direito comunitário em relação às ordens jurídicas nacionais.

\section{A Construção Escalonada da Ordem Jurídica}

O direito comunitário possui, na moldura da construção escalonada da ordem jurídica, ${ }^{5}$ uma primazia prima facie diante do direito nacional dos Estados-Membros. ${ }^{6}$

\footnotetext{
${ }^{1}$ Com respeito à história do Tribunal de Justiça da União Européia, ver, pormenorizadamente, Anthony Arnull, The European Union and its Courts of Justice, 2. ed., New York, 2006, p. 5 ss.

${ }^{2}$ Cf. Rudolf Streinz, Europarecht, 8. ed., Heidelberg, 2008, números de margem 378 s.; Matthias Herdegen, Europarecht, 11. ed., München, 2009, p. 136; Andreas Haratsch/Christian Koenig/Matthias Pechstein, Europarecht, 6. ed., Tübingen, 2009, números de margem 274 s.; Jörg Pirrung, Europäisches Gericht erster Instanz, in: Jürgen Basedow et al. (Orgs.), Handwörterbuch des Europäischen Privatrechts, vol. I, Tübingen, 2009, p. 527 ss.

${ }^{3}$ Cf. Rudolf Streinz, Europarecht, 8. ed., Heidelberg, 2008, número de margem 379; Matthias Herdegen, Europarecht, 11. ed., München, 2009, p. 137.

${ }^{4}$ Cf. Rudolf Streinz, Europarecht, 8. ed., Heidelberg, 2008, número de margem 377; Matthias Herdegen, Europarecht, 11. ed., München, 2009, p. 135; Andreas Haratsch/Christian Koenig/Matthias Pechstein, Europarecht, 6. ed., Tübingen, 2009, números de margem 270 ss.; Jörg Pirrung, Europäischer Gerichtshof, in: Jürgen Basedow et al. (Orgs.), Handwörterbuch des Europäischen Privatrechts, vol. I, Tübingen, 2009, p. 512. ${ }^{5}$ Ver, com respeito à estrutura escalonada da ordem jurídica, Adolf Julius Merkl, Die Lehre von der Rechtskraft, Leipzig/Wien, 1923; Adolf Julius Merkl, Prolegomena einer Theorie des rechtlichen Stufenbaus, in: Dorothea Mayer-Maly et al. (Orgs.), Gesammelte Schriften, vol. I/1, Berlin, 1993, p. 437 ss.; Hans Kelsen, Teoria Pura do Direito, São Paulo, 2003, p. 246 ss. Cf., ainda, Martin Borowski, Die Lehre vom Stufenbau des Rechts nach Adolf Julius Merkl, in: Stanley Paulson/Michael Stolleis (Orgs.), Hans Kelsen
} 


\section{a) A primazia em princípio existente em favor do direito comunitário}

De acordo com o Tribunal de Justiça da União Européia, o direito comunitário ocupa sempre e de modo irrestrito uma posição de primazia em relação às ordens jurídicas nacionais. Isto decorre da autonomia do ordenamento jurídico europeu e do seu caráter de direito comunitário. ${ }^{7}$ O Tribunal Constitucional Federal alemão também parte de uma primazia em princípio existente em favor do direito comunitário, mas identifica a base de legitimação do direito comunitário em uma instrução nacional de aplicação (em virtude da ausência de suficiente legitimidade democrática). ${ }^{8} \mathrm{O}$ art. 23, alínea 1, da Lei Fundamental alemã exige, com respeito à transferência de direitos de soberania, que a União Européia satisfaça exigências estruturais e materiais mínimas e que remanesçam ao legislador nacional competências nacionais de peso substancial. Abstraindo-se destes limites extremos (até agora, teóricos), o direito comunitário desfruta de uma primazia no plano da aplicação, a qual também irradia eficácia diante do direito constitucional nacional.

\section{b) A primazia do direito primário comunitário}

O direito comunitário subdivide-se em direito primário e secundário. ${ }^{9}$ Ambos possuem primazia diante do direito nacional. O direito primário consiste nos tratados celebrados entre os Estados-Membros, especialmente no Tratado de Lisboa, em vigor desde 1.12.2009. ${ }^{10}$ O Tratado de Lisboa compõe-se do Tratado da União Européia (TUE) e do Tratado sobre o Funcionamento da União Européia (TFUE).

Pertencem ao direito comunitário europeu secundário os atos jurídicos promulgados pelos órgãos da União Européia. Nos termos do art. 288 do TFUE, compreendem-se nesta categoria especialmente os regulamentos e as diretivas. Um regulamento possui validade geral. Ele é vinculativo em sua integralidade e vale diretamente em todos os

- Staatsrechtslehrer und Rechtstheoretiker des 20. Jahrhunderts, Tübingen, 2005, p. 122 ss.; Peter Koller, Zur Theorie des rechtlichen Stufenbaues, in: Stanley Paulson/Michael Stolleis (Orgs.), Hans Kelsen Staatsrechtslehrer und Rechtstheoretiker des 20. Jahrhunderts, Tübingen: Mohr Siebeck, 2005, p. 106 ss.; Robert Walter, Der Aufbau der Rechtsordnung, 2. ed., Wien, 1974; Theo Öhlinger, Der Stufenbau der Rechtsordnung - Rechtstheoretische und ideologische Aspekte, Wien, 1975; Heinz Mayer, Die Theorie des rechtlichen Stufenbaues, in: Clemens Jabloner et al. (Orgs.), Schwerpunkte der Reinen Rechtslehre, Wien, 1992, p. 37 ss.; Marietta Auer, A interpretação em conformidade com o direito primário, in: António Pinto Monteiro/Jörg Neuner/Ingo Sarlet (Orgs.), Direitos Fundamentais e Direito Privado - Uma Perspectiva de Direito Comparado, Coimbra, 2007, p. 50 ss.; Theodor Schilling, Rang und Geltung von Normen in gestuften Rechtsordnungen, Berlin, 1994, p. 159 ss., p. 401 ss.

${ }^{6}$ Cf. Rudolf Streinz, Europarecht, 8. ed., Heidelberg, 2008, número de margem 201; Matthias Herdegen, Europarecht, 11. ed., München, 2009, p. 209 ss.; Andreas Haratsch/Christian Koenig/Matthias Pechstein, Europarecht, 6. ed., Tübingen, 2009, número de margem 56, números de margem 187 ss.

7 TJUE (Tribunal de Justiça da União Européia), Processo 6/64 (Costa/E.N.E.L.), de 15.7.1964, Col. (Colectânea da Jurisprudência) 1964, p. 1251 ss. (p. 1269 ss.); TJUE, Processo C-453/99 (Courage) de 20.9.2001, Col. 2001, p. I-6297, número de margem 19.

${ }^{8}$ Cf. o acórdão do Tribunal Constitucional Federal alemão acerca do Tratado de Lisboa: BVerfG, 2 BvE 2/08, de 30.6.2009, NJW 2009, 2267-2295.

${ }^{9}$ Cf. Rudolf Streinz, Europarecht, 8. ed., Heidelberg, 2008, números de margem 2 ss.; Matthias Herdegen, Europarecht, 11. ed., München, 2009, p. 149 ss.; Andreas Haratsch/Christian Koenig/Matthias Pechstein, Europarecht, 6. ed., Tübingen, 2009, número de margem 85, números de margem 323 ss.

${ }^{10}$ Cf. Rudolf Streinz/Christoph Ohler/Christoph Herrmann, Der Vertrag von Lissabon zur Reform der EU, 2. ed., München, 2008; Ingolf Pernice/Miroslav Angelov, Auf dem Weg zum Vertrag von Lissabon, Baden-Baden, 2008; Waldemar Hummer/Walter Obwexer (Orgs.), Der Vertrag von Lissabon, Baden-Baden, 2009. 
Estados-Membros. Diferentemente de um regulamento, uma diretiva não vale, via de regra, diretamente, mas contém uma instrução de transposição para os Estados-Membros individuais. Ela "vincula o Estado-Membro destinatário quanto ao resultado a alcançar, deixando, no entanto, às instâncias nacionais a competência quanto à forma e aos meios”, nos termos do art. 288, alínea 3, do TFUE. Os Estados-Membros precisam, portanto, primeiro transpor os preceitos das diretivas mediante um ato legislativo nacional.

O direito comunitário primário não possui primazia apenas em relação às ordens jurídicas nacionais, mas também ocupa uma posição de superioridade na hierarquia normativa em relação ao direito comunitário secundário. Esta última decorre do caráter semelhante ao direito constitucional do direito primário, especialmente da regulamentação prevista no § 288 do TFUE acerca das competências normativas no plano secundário.

\section{As Especificidades do Direito Comunitário}

O direito comunitário apresenta, do ponto de vista metodológico, sobretudo duas particularidades:

\section{a) A pluralidade linguística}

Afigura-se, em primeiro lugar, significativo o fato de não haver uma língua européia comum. O Tribunal de Justiça da União Européia precisa, por isso, levar em consideração, de modo equivalente, as línguas oficiais dos Estados-Membros (entrementes 23), nos termos do art. 55, alínea 1, do TUE, e realizar uma correspondente comparação textual na moldura do método gramatical de interpretação. ${ }^{11}$ Este fenômeno não é, todavia, singular, já tendo sido abordado no art. 33, alínea 4, da Convenção de Viena sobre o Direito dos Tratados ${ }^{12}$ e ocorre, igualmente, em países com diferentes línguas oficiais. ${ }^{13}$ A pluralidade linguística conduz a uma análise textual mais complexa e trabalhosa, mas pode também trazer a vantagem de que um

${ }^{11}$ Ver, a respeito, pormenorizadamente, Anthony Arnull, The European Union and its Courts of Justice, 2. ed., New York, 2006, p. 608 ss., com documentação comprobatória adicional. Cf., ainda, Isabel Schübel-Pfister, Sprache und Gemeinschaftsrecht, Berlin, 2004, p. 37 ss.; Franz C. Mayer, Europäisches Sprachenverfassungsrecht, Der Staat 44 (2005), p. 367 ss.; Hans-Martin Gebauer, Europa und seine Sprachen, Merkur 60 (2006), p. 642 ss.; Fabrizio Vismara, The Role of the Court of Justice of the European Communities in the Interpretation of Multilingual Texts, in: Barbara Pozzo/Valentina Jacometti (Orgs.), Multilingualism and the Harmonization of European Law, Alphen aan den Rijn, 2006, p. 61 ss.

12 “Artigo 33 - Interpretação de Tratados Autenticados em duas ou mais Línguas.

1. Quando um tratado foi autenticado em duas ou mais línguas, seu texto faz igualmente fé em cada uma delas, a não ser que o tratado disponha ou as partes concordem que, em caso de divergência, prevaleça um texto determinado.

2. Uma versão do tratado em língua diversa daquelas em que o texto foi autenticado só será considerada texto autêntico se o tratado o previr ou as partes nisso concordarem.

3. Presume-se que os termos do tratado têm o mesmo sentido nos diversos textos autênticos.

4. Salvo o caso em que um determinado texto prevalece nos termos do parágrafo 1, quando a comparação dos textos autênticos revela uma diferença de sentido que a aplicação dos artigos 31 e 32 não elimina, adotar-se-á o sentido que, tendo em conta o objeto e a finalidade do tratado, melhor conciliar os textos." Convenção de Viena sobre o Direito dos Tratados. Disponível em: <http://www2.mre.gov.br/dai/dtrat.htm>. Acesso em: 14 dez. 2009.

${ }^{13}$ Ver, exemplificativamente, com respeito às três línguas oficiais da Suíca, Ernst A. Kramer, Juristische Methodenlehre, 2. ed., Bern, 2005, p. 68 s. 
significado literal desprovido de clareza ou difuso pode ser elucidado por intermédio de um sentido literal mais claro e preciso existente em outra língua oficial.

\section{b) A competência limitada de regulamentação}

Em segundo lugar, afigura-se característico o fato de a União Européia, diferentemente dos Estados-Membros, não dispor de uma competência-competência, i. e., não poder ela, por si só, ampliar suas próprias competências (em relação aos Estados-Membros). Vale, antes o contrário, o princípio da atribuição de competências por intermédio dos Estados-Membros. ${ }^{14}$ Mesmo este não constitui, é bem verdade, um fenômeno novo, podendo ocorrer também no âmbito da legislação concorrente entre um Estado federal e seus Estados federados singulares. ${ }^{15}$ Uma restrição adicional de competência é promovida pelo princípio da subsidiariedade, nos termos do art. 5, alínea 1, frase 2 e alínea 3, do TUE. ${ }^{16}$ De acordo com este dispositivo, a União "intervém apenas se e na medida em que os objectivos da aç̧ão considerada não possam ser suficientemente alcançados pelos Estados-Membros, tanto ao nível central como ao nível regional e local, podendo contudo, devido às dimensões ou aos efeitos da acção considerada, ser mais bem alcançados ao nível da União”. Esta restrição de competência realizada pelo princípio da subsidiariedade vale não apenas para os Poderes Legislativo e Executivo, devendo também o Judiciário atentar a este limite por ocasião do desenvolvimento judicial do direito. O Tribunal de Justiça da União Européia não deve, portanto, determinar consequências jurídicas que também não possam ser promulgadas como normas jurídicas pelo legislador comunitário. ${ }^{17}$

\section{As Competências do Tribunal de Justiça da União Européia}

As competências do Tribunal de Justiça da União Européia estendem-se sobretudo a dois âmbitos, nos termos do art. 19 do TUE c/c os arts. 251 e ss. do TFUE. ${ }^{18}$

a) O Tribunal de Justiça da União Européia como instância controladora

O Tribunal de Justiça da União Européia tem, de um lado, a tarefa de zelar pelo cumprimento do Tratado por parte dos Estados-Membros. Por outro lado, o Tribunal tem a missão de exercer vigilância com respeito à validade da atuação dos órgãos

\footnotetext{
${ }^{14}$ Cf. Rudolf Streinz, Europarecht, 8. ed., Heidelberg, 2008, números de margem 147 ss., número de margem 413, números de margem 498 s.; Matthias Herdegen, Europarecht, 11. ed., München, 2009, p. 176 ss.; Andreas Haratsch/Christian Koenig/Matthias Pechstein, Europarecht, 6. ed., Tübingen, 2009, números de margem 166 ss.; Carsten Herresthal, Rechtsfortbildung im europarechtlichen Bezugsrahmen, München, 2006, p. 159; Clemens Höpfner, Die systemkonforme Auslegung, Tübingen, 2008, p. 66.

${ }^{15}$ Cf., acerca da competência para legislação concorrente no Brasil, art. 24 da Constituição Federal de 1988.

${ }^{16}$ Cf. Rudolf Streinz, Europarecht, 8. ed., Heidelberg, 2008, número de margem 39, número de margem 166; Matthias Herdegen, Europarecht, 11. ed., München, 2009, p. 93 ss.; Andreas Haratsch/Christian Koenig/Matthias Pechstein, Europarecht, 6. ed., Tübingen, 2009, números de margem 174 ss.; Carsten Herresthal, Rechtsfortbildung im europarechtlichen Bezugsrahmen, München, 2006, p. 153; Clemens Höpfner, Die systemkonforme Auslegung, Tübingen, 2008, p. 66.

${ }^{17}$ Ver, pormenorizadamente, Jörg Neuner, in: Karl Riesenhuber (Org.), Europäische Methodenlehre, 2. ed., Berlin, 2010, § 13, número de margem 15, com documentação comprobatória adicional.

${ }^{18}$ Cf., a título exemplificativo, com respeito ao Tribunal de Justiça da União Européia como intérprete e aplicador do direito comunitário europeu na produção bibliográfica luso-brasileira: Fausto de Quadros, Direito da União Europeia, Coimbra, 2008, p. 455 ss.; Jorge Fontoura, A Construção Jurisprudencial do Direito Comunitário Europeu, Revista de Informação Legislativa vol. 140 (1998), p. 163 ss.
} 
comunitários, nomeadamente em relação à juridicidade dos atos legislativos. Neste sentido, pode o Tribunal, nos termos do art. 264, alínea 1, do TFUE, por exemplo, declarar nula uma norma do direito comunitário secundário.

b) O Tribunal de Justiça da União Européia como instância interpretativa

De modo correspondente à visão clássica da doutrina da separação dos poderes, o Tribunal tem, além disso, a tarefa de interpretar a totalidade do direito comunitário de modo vinculativo. O Tribunal garante, nos termos do art. 19, alínea 1, do TUE, "o respeito do direito na interpretação e aplicação dos Tratados”. Isto abrange, para além da mera interpretação do direito legislado orientada ao sentido literal da norma, também a competência para o desenvolvimento judicial do direito (interpretação extensiva), na medida em que o direito comunitário contenha uma lacuna de regulamentação contrária ao plano. ${ }^{19}$ Neste sentido, destaca também o Tribunal: "Consoante jurisprudência reiterada, hão de ser considerados na interpretação de um preceito jurídico-comunitário não apenas o seu sentido literal, mas também o seu contexto e as finalidades perseguidas com a regulamentação da qual ele faz parte”. ${ }^{20}$

Os tribunais nacionais, inclusive os tribunais constitucionais, têm, nos termos do art. 267, alíneas 2 e 3, do TFUE, competência e - na medida em que estejam decidindo em última instância - são obrigados a remeter a questão para o Tribunal de Justiça da União Européia com a finalidade de obter uma decisão prévia acerca da interpretação do direito comunitário primário, bem como da interpretação e validade do direito comunitário secundário. ${ }^{21}$ Não há necessidade de levar a cabo uma remessa, nos termos da doutrina do "acte-clair” do Tribunal de Justiça da União Européia, excepcionalmente, “quando o preceito jurídico-comunitário em apreço já tiver sido objeto de interpretação pelo Tribunal ou (...) a correta aplicação do direito comunitário for de tal forma evidente, que não haja espaço para uma dúvida razoável”. ${ }^{22}$

\section{A VINCULAÇÃO À LEI}

A vinculação do Tribunal de Justiça da União Européia ao direito comunitário possui três dimensões: uma relativa às competências, outra relativa ao conteúdo e outra temporal.

\footnotetext{
${ }^{19}$ Cf. Rudolf Streinz, Europarecht, 8. ed., Heidelberg, 2008, números de margem 567 ss.; Matthias Herdegen, Europarecht, 11. ed., München, 2009, p. 187 ss.; Andreas Haratsch/Christian Koenig/Matthias Pechstein, Europarecht, 6. ed., Tübingen, 2009, número de margem 408; Carsten Herresthal, Rechtsfortbildung im europarechtlichen Bezugsrahmen, München, 2006; Clemens Höpfner, Die systemkonforme Auslegung, Tübingen, 2008, p. 235; Hannes Rösler, Auslegung des Gemeinschaftsrechts, in: Jürgen Basedow et al. (Orgs.), Handwörterbuch des Europäischen Privatrechts, vol. I, Tübingen, 2009, p. 123.

${ }^{20}$ TJUE, Processos C-14/06 e C-295/06 (Parlamento/Comissão), de 1º.04.2008, Col. 2008, p. I-1649, número de margem 67 , com documentação comprobatória adicional.

${ }^{21}$ Cf. Rudolf Streinz, Europarecht, 8. ed., Heidelberg, 2008, números de margem 630 ss.; Matthias Herdegen, Europarecht, 11. ed., München, 2009, p. 201 ss.; Andreas Haratsch/Christian Koenig/Matthias Pechstein, Europarecht, 6. ed., Tübingen, 2009, números de margem 495 ss.; Franz C. Mayer, Verfassungsgerichtsbarkeit, in: Armin von Bogdandy/Jürgen Bast (Orgs.), Europäisches Verfassungsrecht, 2. ed., Berlin, 2009, p. 562 ss.; Jörg Pirrung, Europäischer Gerichtshof, in: Jürgen Basedow et al. (Orgs.), Handwörterbuch des Europäischen Privatrechts, vol. I, Tübingen, 2009, p. 513.

${ }^{22}$ TJUE, Processo 283/81 (C.I.L.F.I.T.), de 6.10.1982, Col. 1982, p. 3415, número de margem 21; ver, ainda, Anthony Arnull, The European Union and its Courts of Justice, 2. ed., New York, 2006, p. 626 s., com documentação comprobatória adicional.
} 


\section{A dimensão relativa às competências}

Do ponto de vista das competências, afigura-se característico o fato de o Tribunal de Justiça da União Européia não estar vinculado apenas aos preceitos do legislador comunitário, devendo ele, simultaneamente, levar também em consideração a competência limitada de regulamentação deste último.

\section{a) $\mathbf{O}$ equilíbrio institucional}

O chamado princípio do equilíbrio institucional constitui a contrapartida jurídico-comunitária da visão clássica da separação dos poderes, na medida em que ele fixa a estrutura de competências dos órgãos comunitários uns em relação aos outros. ${ }^{23}$ Para o Poder Judiciário, decorre deste princípio do “equilíbrio institucional” o dever de respeitar sobretudo a prerrogativa decisória do legislador comunitário, eis que, de outro modo, este último restaria desprovido de qualquer função como instância criadora do direito. O Tribunal de Justiça da União Européia está, portanto, em princípio vinculado ao direito comunitário e não deve atuar na arena política.

\section{b) A competência concorrente de regulamentação}

Em virtude das competências limitadas da Comunidade, o Tribunal tem ainda a tarefa de controlar a observância dos princípios da atribuição de competências e da subsidiariedade. Outra consequência consiste no dever de o Tribunal também levar em consideração estes preceitos em relação à sua própria atuação e de não perder de vista ambos os limites atinentes às competências em se tratando de suas próprias decisões. ${ }^{24}$

\section{A dimensão relativa ao conteúdo}

Do ponto de vista relativo ao conteúdo, a vinculação à lei significa que o Tribunal de Justiça da União Européia deve interpretar e aplicar (lege artis) o direito comunitário.

\section{a) Os cânones de interpretação}

O sentido literal da lei constitui também para o Tribunal de Justiça da União Européia o ponto de partida da interpretação. ${ }^{25}$ Em se tratando, nomeadamente, de

${ }^{23}$ Cf. TJUE, Processo C-133/06 (Parlamento/Conselho), de 6.5.2008, Col. 2008, p. I-3189, números de margem 56 s.; TJUE, Processo C-70/88 (Parlamento/Conselho), de 22.5.1990, Col. 1990, p. I-2041, números de margem 21 ss.; com respeito à viabilidade de comparação com a tradicional separação de poderes, ver, pormenorizadamente, Peter Häberle, Europäische Verfassungslehre, 6. ed., Baden-Baden, 2009, p. 422 ss. Cf. ainda, Rudolf Streinz, Europarecht, 8. ed., Heidelberg, 2008, número de margem 566; Matthias Herdegen, Europarecht, 11. ed., München, 2009, p. 147; Andreas Haratsch/Christian Koenig/Matthias Pechstein, Europarecht, 6. ed., Tübingen, 2009, números de margem 166 ss.

${ }^{24}$ Ver, a respeito do assunto, pormenorizadamente, Jörg Neuner, in: Karl Riesenhuber (Org.), Europäische Methodenlehre, 2. ed., Berlin: De Gruyter, 2010, §13, número de margem 15, com documentação comprobatória adicional.

${ }^{25}$ Ver, apenas de modo exemplificativo, TJUE, Processo 55/81 (Levin), de 23.03.1982, Col. 1982, p. 1035, número de margem 9; ver, ainda, Ninon Colneric, EuZA 2008, p. 212 ss. (p. 216), com documentação comprobatória adicional; Rudolf Streinz, Europarecht, 8. ed., Heidelberg, 2008, número de margem 570; Matthias Herdegen, Europarecht, 11. ed., München, 2009, p. 187; Carsten Herresthal, Rechtsfortbildung im europarechtlichen Bezugsrahmen, München, 2006, p. 59; Hannes Rösler, Auslegung des Gemeinschaftsrechts, in: Jürgen Basedow et al. (Orgs.), Handwörterbuch des Europäischen Privatrechts, vol. I, Tübingen, 2009, p. 122. 
proibições de analogia, o sentido literal ainda possível pode constituir um limite às decisões admissíveis (por exemplo, no caso da imposição de multas). ${ }^{26}$ Para além do princípio “nulla poena sine lege stricta”, afigura-se indicada uma proibição de analogia para intervenções impositoras de ônus sobre os cidadãos. Assim, por exemplo, o Tribunal rejeita, no âmbito do direito relativo ao recolhimento de taxas, uma aplicação analógica de regras que onerem os cidadãos individuais. ${ }^{27}$

A interpretação não deve se limitar ao significado gramatical, mas também precisa levar em consideração todo o contexto de significação dentro do qual o preceito singular está inserido. Isto é, em primeira linha, um prosseguimento da interpretação gramatical, mas vai, em seguida, na direção de uma interpretação sistemática em sentido estrito. Na interpretação sistemática, trata-se de compreender um preceito singular como parte integrante dos sistemas jurídico interno e externo e, em decorrência da posição por ele ocupada nesta totalidade de regulamentação, extrair conclusões relativas ao seu sentido e finalidade. ${ }^{28}$ Os preceitos singulares não se encontram isolados uns ao lado dos outros, mas são intentados pelo legislador como uma totalidade coerente, desprovida de contradições e ordenada de acordo com princípios. ${ }^{29} \mathrm{Um}$ caso especial de interpretação sistemática constitui a interpretação do direito secundário conforme o direito primário. ${ }^{30}$ Trata-se, aqui, de uma máxima semelhante à do dever de interpretação conforme a Constituição no direito nacional. ${ }^{31} \mathrm{O}$ dever de interpretação conforme o direito primário decorre sobretudo do pensamento de sistema, bem como da autoridade do legislador de direito primário (i. e., dos Estados-Membros - ou seja - das partes signatárias do Tratado). Uma interpretação conforme o direito primário afigura-se, todavia, apenas admissível de modo subsidiário, após a identificação da ausência de uma intenção regulamentadora concreta do legislador comunitário de direito secundário; além disso, uma tal interpretação não deve perder de vista os limites das decisões contra legem. Caso o legislador de direito secundário persiga uma finalidade ilícita, o Tribunal de Justiça da União Européia deve declarar a respectiva norma ineficaz. Uma substituição da norma por iniciativa própria do Tribunal desprezaria, em havendo opções alternativas de regulamentação por parte do legislador, o princípio do equilíbrio institucional. Havendo, em contrapartida, mais de uma opção

${ }^{26}$ Cf. TJUE, Processo 117/83 (Könecke), de 25.09.1984, Col. 1984, p. 3291, números de margem 11, 13, 16.

${ }^{27}$ TJUE, Processo 325/85 (Irlanda/Comissão), de 15.12.1987, Col. 1987, p. 5041, número de margem 18.

${ }^{28}$ Ver, pormenorizadamente, Karl Riesenhuber, in: Karl Riesenhuber (Org.), Europäische Methodenlehre, 2. ed., Berlin, 2010, § 11, números de margem 23 ss.

${ }^{29}$ Cf. TJUE, Processo 283/81 (C.I.L.F.I.T.), de 6.10.1982, Col. 1982, p. 3415, número de margem 20.

${ }^{30}$ Cf. Marietta Auer, A interpretação em conformidade com o direito primário, in: António Pinto Monteiro/Jörg Neuner/Ingo Sarlet (Orgs.), Direitos Fundamentais e Direito Privado - Uma Perspectiva de Direito Comparado, Coimbra, 2007, p. 41 ss.; Clemens Höpfner, Die systemkonforme Auslegung, Tübingen, 2008, p. 217 ss., p. 220 ss.

${ }^{31}$ Cf. com respeito à interpretação conforme a Constituição no direito brasileiro, a título meramente ilustrativo, Gilmar Ferreira Mendes, Die abstrakte Normenkontrolle vor dem Bundesverfassungsgericht und vor dem brasilianischen Supremo Tribunal Federal, Berlin, 1991, p. 203 ss.; Paulo Bonavides, A presunção de constitucionalidade das leis e interpretação conforme a Constituição, in: Paulo Bonavides, Teoria da Democracia Participativa, São Paulo, 2001, p. 235 ss.; Virgílio Afonso da Silva, Interpretação conforme a constituição: entre a trivialidade e a centralização judicial, Revista Direito GV vol. 3 (2006), p. 191 ss. 
de interpretação, deve ser dada preferência àquela que for compatível com o direito primário. ${ }^{32}$

Com respeito à interpretação histórica, havia, de início, a dificuldade de os trabalhos preparatórios dos Tratados não terem sido publicados. Nos atos legislativos mais recentes, especialmente no caso do Tratado de Lisboa, os materiais legislativos são, todavia, acessíveis a todos e podem ser utilizados pelos tribunais na interpretação. ${ }^{33}$ No âmbito do direito comunitário secundário, a reconstrução da vontade histórica do legislador também foi facilitada, na medida em que, nos termos do art. 296, alínea 2, do TFUE, há um dever de fundamentação para os atos jurídicos e, além disso, os documentos devem ser disponibilizados ao público, nos termos do art. 15 do TFUE.

Na moldura da interpretação teleológica, o Tribunal de Justiça da União Européia orienta-se a partir de duas máximas interpretativas especiais. ${ }^{34}$ De um lado, tem-se o princípio do "effet utile", i. e., há de ser escolhida a interpretação que mais promova a realização dos objetivos do Tratado. ${ }^{35}$ Por outro lado, o Tribunal defende a doutrina dos "implied powers", segundo a qual os preceitos relativos às competências devem ser interpretados de modo a abranger também competências não-expressas, sem as quais o exercício das competências explicitamente regulamentadas não seria possível ou tornar-se-ia absurdo. ${ }^{36}$

\section{b) A finalidade da interpretação}

O direito comunitário deve ser interpretado, em primeira linha, de modo autônomo, i. e., desvinculado do entendimento dos Estados-Membros individuais. ${ }^{37}$ Do mesmo modo que na interpretação do direito nacional, deve-se, todavia, interpretar também o direito comunitário, em primeira linha, de modo subjetivo-teleológico. ${ }^{38}$ A primazia da interpretação histórica decorre sobretudo dos princípios da democracia, do equilíbrio institucional e da transparência metodológica. A jurisprudência do Tribunal

${ }^{32}$ Cf. TJUE, Processo 218/82 (Comissão/Conselho), de 13.12.1983, Col. 1983, p. 4063, número de margem 15.

${ }^{33}$ Tratado de Lisboa. Base de Dados. Disponível em

$<$ http://www.consilium.europa.eu/App/Cig/Cig2007.aspx?modeCIG=register\&lang=PT\&cmsid=1300>.

Acesso em: 14 dez. 2009.

${ }^{34}$ Cf. Rudolf Streinz, Europarecht, 8. ed., Heidelberg, 2008, número de margem 444; Matthias Herdegen, Europarecht, 11. ed., München, 2009, p. 187; Andreas Haratsch/Christian Koenig/Matthias Pechstein, Europarecht, 6. ed., Tübingen, 2009, número de margem 182, número de margem 173; Carsten Herresthal, Rechtsfortbildung im europarechtlichen Bezugsrahmen, München, 2006, p. 107, p. 140, nota de rodapé 166.

${ }^{35}$ Fundamental: TJUE, Processo 9/70 (“Leberpfennig”), de 6.10.1970, Col. 1970, p. 825, número de margem 5.

${ }^{36}$ Ver, por exemplo, TJUE, Processo C-476/98 (“Open Skies”), de 5.11.2002, Col. 2002, p. I-9855, número de margem 82; TJUE, Processo 8/55 (Fédéchar), de 29.11.1956, Col. 1956, p. 297 (p. 311 s.).

37 Por fim: TJUE, Processo C-208/07 (von Chamier-Glisczinski), de 16.7.2009, (ainda não consta em coletânea) número de margem 48; TJUE, Processo 327/82 (Ekro), de 18.1.1984, Col. 1984, p. 107, número de margem 11.

${ }^{38}$ Ver, pormenorizadamente, Jörg Neuner, Privatrecht und Sozialstaat, München, 1998, p. 190 ss.; Clemens Höpfner/Bernd Rüthers, AcP 209 (2009), p. 1 ss. (p. 13 ss., p. 35). Cf., em sentido diverso, ClausWilhelm Canaris, Die richtlinienkonforme Auslegung und Rechtsfortbildung im System der juristischen Methodenlehre. in: Helmut Koziol/Peter Rummel (Orgs.), Festschrift für Franz Bydlinski, Wien, 2002, p. 47 ss. (p. 69, p. 87); Carsten Herresthal, Rechtsfortbildung im europarechtlichen Bezugsrahmen, München: C. H. Beck, 2006, p. 319, bem como os demais autores mencionados na nota de rodapé 156. 
de Justiça da União Européia a respeito da finalidade primacial da interpretação afigura-se inconsistente. Em decisões mais recentes, o Tribunal asseverou, todavia, mais uma vez, que os preceitos de direito comunitário “(devem) ser interpretados segundo a real vontade do seu autor e o fim por ele perseguido, nomeadamente à luz de sua redação em todas as línguas”. ${ }^{39}$

\section{c) Analogia e restrição}

O enunciado da igualdade em sua dimensão positiva impõe que pressupostos de fato similares sejam tratados de modo equivalente; portanto, que a consequência jurídica C não valha apenas para o pressuposto de fato regulamentado por lei P1, mas também de modo análogo para o pressuposto de fato similar P2. ${ }^{40}$ Tais conclusões por analogia são frequentemente encontradas na jurisprudência do Tribunal de Justiça da União Européia. Um exemplo consiste em uma recente decisão relativa aos deveres de indenização no âmbito do transporte aéreo. O Tribunal de Justiça da União Européia desenvolve nesta decisão, primeiramente, a diferenciação entre a anulação e o atraso de um vôo; em seguida, assevera que uma pretensão de indenização por atrasos “não (decorre) diretamente do sentido literal do Regulamento no 261/2004"; por fim, extrai a seguinte conclusão por semelhança: "Devido ao fato de os danos sofridos pelos passageiros no caso de uma anulação e de um atraso serem semelhantes, os passageiros de vôos atrasados e anulados não podem ser tratados diferentemente sem que seja violado o princípio da igualdade de tratamento". ${ }^{41}$

O enunciado da igualdade em sua dimensão negativa impõe que situações distintas sejam tratadas diferentemente. Consequentemente, o Tribunal de Justiça da União Européia não lança mão apenas de um desenvolvimento judicial do direito que ultrapassa o sentido literal mediante conclusão analógica, mas também, na direção contrária, de uma interpretação restritiva, ${ }^{42}$ a qual também pode ser caracterizada metodologicamente como redução teleológica, porque e na medida em que o texto normativo tenha sido redigido de modo demasiadamente amplo e careça de uma necessária restrição.

${ }^{39}$ TJUE, Processo C-188/03 (Junk), de 27.01.2005, Col. 2005, p. I-885, número de margem 33, com documentação comprobatória adicional.

${ }^{40}$ Cf. Hans-Joachim Koch/Helmut Rüßmann, Juristische Begründungslehre, München, 1982, p. 257 ss.; Karl Larenz, Methodenlehre der Rechtswissenschaft, 6. ed., Berlin et al., 1991, p. 381 ss.; Franz Bydlinski, Juristische Methodenlehre und Rechtsbegriff, 2. ed., Wien/New York, 1991, p. 475 ss. Cf. ainda, no âmbito da literatura jurídica anglo-americana, Zenon Bankowski, Analogical Reasoning and Legal Institutions, in: Zenon Bankowski/Ian White/Ulrike Hahn (Orgs.), Informatics and the Foundations of Legal Reasoning, Dordrecht, 1995, p. 177 ss.; Cass Sunstein, Legal Reasoning and Political Conflict, New York, 1996, p. 62 ss.; Scott Brewer, Exemplary Reasoning: Semantics, Pragmatics, and the Rational Force of Legal Argument by Analogy, 109 Harvard Law Review (1996), p. 923 ss. Cf., por fim, com ênfase no direito europeu, Katja Langenbucher, Argument by Analogy in European Law, The Cambridge Law Journal vol. 57 (1998), p. 481 ss.; Carsten Herresthal, Rechtsfortbildung im europarechtlichen Bezugsrahmen, München, 2006, p. 239 ss., p. 335 ss.

${ }^{41}$ TJUE, Processos C-402/07 e C-432/07 (Sturgeon), de 19.11.2009 (ainda não constam em coletânea), números de margem $60,41,39$

${ }^{42}$ Cf., por exemplo, TJUE, Processos C-14/06 e C-295/06 (Parlamento/ Comissão), de 1.4.2008, Col. 2008, p. I-1649, números de margem 65 ss., 71; TJUE, Processo C-183/90 (van Dalfsen et al.), de 4.10.1991, Col. 1991, p. I-4743, números de margem 19 ss. 


\section{A dimensão temporal}

Com respeito à vinculação à lei, também deve ser levado em consideração, por fim, o fato de as leis poderem desenvolver tanto efeitos ultra-ativos como retroativos.

a) $O$ efeito ultra-ativo

De acordo com a jurisprudência reiterada do Tribunal de Justiça da União Européia, as leis que ainda não entraram em vigor mas já foram publicadas não dão azo uma eficácia geral bloqueadora, no sentido de uma proibição geral de desenvolvimento judicial do direito. ${ }^{43} \mathrm{~A}$ jurisprudência não deve, todavia, obstruir a finalidade legislativa estabelecida pela nova regulamentação (trata-se da chamada proibição de frustração). ${ }^{44}$

Além de uma eficácia bloqueadora, futuras normas jurídicas também podem influenciar positivamente uma interpretação extensiva. Elas podem inspirar e legitimar a jurisprudência na condição de "soft laws".

\section{b) $O$ efeito retroativo}

Diferentemente de um efeito ultra-ativo, o efeito retroativo refere-se a um comando de aplicação relativo a uma lei em vigor. De acordo com o Tribunal de Justiça da União Européia, o princípio da segurança jurídica proíbe, de regra, um efeito retroativo (verdadeiro), a não ser que a retroatividade seja necessária tendo em vista a finalidade pretendida e seja devidamente levada em conta a confiança legítima dos cidadãos atingidos. ${ }^{45}$

\section{A VINCULAÇÃO AOS PRECEDENTES}

43 TJUE, Processo C-212/04 (Adeneler), de 4.07.2006, Col. 2006, p. I-6057, número de margem 122 (Obrigação de omissão [de adotar disposições capazes de comprometer os objetivos de uma diretiva que esteja em curso de transposição] vale também para tribunais nacionais); TJUE, Processo C-144/04 (Mangold), de 22.11.2005, Col. 2005, p. I-9981, número de margem 68 (independentemente se a regulamentação nacional objetiva ou não a transposição [da diretiva]); TJUE, Processo C-129/96 (Inter-Environnement Wallonie), de 18.12.1997, Col. 1997, p. I-7411, números de margem 35 ss., 44 s. Cf. a respeito, Rudolf Streinz, Europarecht, 8. ed., Heidelberg, 2008, número de margem 460; Matthias Herdegen, Europarecht, 11. ed., München, 2009, p. 165; Andreas Haratsch/Christian Koenig/Matthias Pechstein, Europarecht, 6. ed., Tübingen, 2009, número de margem 338; Carsten Herresthal, Rechtsfortbildung im europarechtlichen Bezugsrahmen, München, 2006, p. 259; Clemens Höpfner, Die systemkonforme Auslegung, Tübingen, 2008, p. 291.

${ }^{44}$ Cf. a proibição paralela de direito internacional, prevista no art. 18 da Convenção de Viena sobre o Direito dos Tratados: “Artigo 18. Obrigação de não Frustrar o Objeto e Finalidade de um Tratado antes de sua Entrada em Vigor.

Um Estado é obrigado a abster-se da prática de atos que frustrariam o objeto e a finalidade de um tratado, quando:

a) tiver assinado ou trocado instrumentos constitutivos do tratado, sob reserva de ratificação, aceitação ou aprovação, enquanto não tiver manifestado sua intenção de não se tornar parte no tratado; ou

b) tiver expressado seu consentimento em obrigar-se pelo tratado no período que precede a entrada em vigor do tratado e com a condição de esta não ser indevidamente retardada." Convenção de Viena sobre o Direito dos Tratados. Disponível em: <http://www2.mre.gov.br/dai/dtrat.htm>. Acesso em: 14 dez. 2009”. ${ }^{45}$ TJUE, Processo C-459/02 (Gerekens e Procola), de 15.07.2004, Col. 2004, p. I-7315, números de margem 22 s.; TJUE, Processo 98/78 (Racke), de 25.01.1979, Col. 1979, p. 69, número de margem 20. 
O Tribunal de Justiça da União Européia está vinculado não apenas aos preceitos legislativos, mas parcialmente também aos precedentes.

\section{A tomada de decisão concreta e individual}

Diferentemente da eficácia abstrata e genérica dos atos legislativos, a tarefa do Tribunal se limita à tomada de uma decisão concreta e individual. Afigura-se característico, do ponto de vista funcional, o fato de o Tribunal não dispor de nenhum direito próprio de iniciativa e depender do diálogo com as partes do processo. Do ponto de vista institucional, falta aos juízes uma legitimação democrática direta, bem como, do ponto de vista organizatório, o aparato que lhes permita desempenhar tarefas legislativas.

\section{O princípio da liberdade decisória}

Diferentemente dos sistemas de common law, não há no direito comunitário uma vinculação estrita aos precedentes, no sentido de uma barreira ao desenvolvimento judicial do direito. ${ }^{46}$ Desse modo, evita-se o risco de uma petrificação da jurisprudência, viabilizando-se que entendimentos jurídicos que venham a ser considerados mais corretos possam se consolidar. De modo consequente, o Tribunal não se vê, em princípio, impedido de levar a cabo um desenvolvimento judicial do direito em virtude da existência de julgados próprios divergentes. ${ }^{47}$

\section{O princípio da proteção da confiança}

Apesar de o Tribunal de Justiça da União Européia tomar apenas decisões de caráter concreto e individual, afigura-se significativo o fato de sua jurisprudência desenvolver uma eficácia bastante ampla na vida jurídica e constituir uma fonte "fática” do direito. ${ }^{48}$ Os cidadãos da União Européia orientam-se a partir dos julgados do Tribunal e esperam segurança jurídica por intermédio do igual tratamento de casos similares. ${ }^{49}$ De regra, também o Tribunal se orienta, por conseguinte, a partir de sua jurisprudência pregressa. Um pressuposto de fato ensejador de confiança

\footnotetext{
${ }^{46}$ Cf. Joxerramon Bengoetxea, The Legal Reasoning of the European Court of Justice - Towards a European Jurisprudence, Oxford, 1993, p. 69; Stefan Vogenauer, Rule of Precedent, in: Jürgen Basedow et al. (Orgs.), Handwörterbuch des Europäischen Privatrechts, vol. II, Tübingen, 2009, p. 1172.

${ }^{47}$ Ver, pormenorizadamente, Anthony Arnull, The European Union and its Courts of Justice, 2. ed., New York, 2006, p. 629 s.; Günter Hager, Rechtsmethoden in Europa, Tübingen, 2009, p. 254 s.; Stefan Vogenauer, Rule of Precedent, in: Jürgen Basedow et al. (Orgs.), Handwörterbuch des Europäischen Privatrechts, vol. II, Tübingen, 2009, p. 1172.

${ }^{48}$ Cf., de modo geral, com respeito às fontes do direito, Konrad Zweigert/Hein Kötz, Einführung in die Rechtsvergleichung, 3. ed., Tübingen, 1996, p. 34 ss., p. 71 ss.; Stefan Vogenauer, Sources of Law and Legal Method in Comparative Law, in: Mathias Reimann/Reinhard Zimmermann (Orgs.), The Oxford Handbook of Comparative Law, Oxford, 2008, p. 869 ss. Cf. ainda, mais especificamente sobre o direito judicial como fonte do direito, Franz Bydlinski, Hauptpositionen zum Richterrecht, JZ 1985, p. 149 ss.; Bernd Rüthers, Richterrecht als Methoden- und Verfassungsproblem, in: Franz Gamillscheg et al. (Orgs.), Festschrift für Karl Molitor zum 60. Geburtstag, München, 1988, p. 293 ss.; John Bell, Judicial Law-making, in: Peter Cane/Joanne Conaghan (Orgs.), The New Oxford Companion to Law, Oxford, 2008, p. 653; Stefan Vogenauer, Richterrecht, in: Jürgen Basedow et al. (Orgs.), Handwörterbuch des Europäischen Privatrechts, vol. II, Tübingen, 2009, p. 1305

${ }^{49} \mathrm{O}$ Tribunal de Justiça da União Européia precisa, por isso, justificar suas decisões de modo correspondente; cf., pormenorizadamente, Joxerramon Bengoetxea, The Legal Reasoning of the European Court of Justice - Towards a European Jurisprudence, Oxford, 1993, p. 116 s., p. 141 ss.
} 
pode ser fundamentado já com base em uma única decisão e sedimentar-se por intermédio da reiteração jurisprudencial. Ele adquire ainda mais intensidade quando a jurisprudência for amplamente referendada pela ciência jurídica. Uma proteção da confiança baseada na jurisprudência pode, todavia, cair por terra quando uma decisão não corporifica um pressuposto de fato ensejador de confiança, pelo fato de ela ser, por exemplo, contraditória em si mesma ou quando aquele que investe a confiança tiver se comportado de maneira desleal. As expectativas de continuidade deflagradas pelos precedentes do Tribunal não são, portanto, grandezas fixas, mas variáveis, as quais devem ser ponderadas com a pretensão concorrente a uma decisão materialmente correta. ${ }^{50}$ Nos raros casos em que o Tribunal até agora alterou sua jurisprudência, isto ocorreu de modo retroativo, i. e., com eficácia não apenas para as decisões futuras no sentido um mero prospective overruling. ${ }^{51}$

\section{CONSIDERAÇÕES FINAIS}

De acordo com o art. 19, alínea 1, frase 2, do TUE, o Tribunal de Justiça da União Européia deve garantir o "respeito do direito". Ele não se submete, assim, a um judicial self-restraint e não deve ficar aquém de suas competências. Por outro lado, o Tribunal está vinculado ao direito comunitário primário e secundário e também não deve extrapolar suas competências. Deve-se atentar, aqui, especialmente aos princípios da separação horizontal e vertical de poderes, bem como da proteção da confiança.

${ }^{50}$ Cf. Katja Langenbucher, JZ 2003, p. 1132, p. 1134 ss.; Katja Langenbucher, Die Entwicklung und Auslegung von Richterrecht, München, 1996, p. 121 ss.

${ }^{51}$ Cf. Franz Bydlinski, JBl. 2001, p. 1, p. 26; Verena Klappstein, Die Rechtsprechungsänderung mit Wirkung für die Zukunft, Berlin, 2009, p. 209 ss. 